\title{
Design, synthesis of nitrogen-rich triazine derivatives and its application in water sample, Vegetables and Oil Product
}

\author{
Ma Xuelin ${ }^{1}$, Zhang Xiaoyong ${ }^{2},{\text { Han } \operatorname{Limin}^{1} \text {, and Hao Zhanzhong}}^{2}$ \\ ${ }^{1}$ Inner Mongolia University of Technology \\ ${ }^{2}$ Baotou Teachers College
}

October 20, 2020

\begin{abstract}
A triazine nitrogen-rich derivative fluorescent probe, 1,1'-(6-chloro-1,3,5-triazine-2,4-diyl)bis(1H-benzo[d][1,2,3]triazole)(L), has been synthesized and successfully achieved for the efficient detection for $\mathrm{Fe} 3+$, Cr2O72-, nitrobenzene as a turn-off chemosensor in $\mathrm{DMF} / \mathrm{H} 2 \mathrm{O}$. The quenching constant(Ksv) and detection of limit for Fe3+, Cr2O72-, nitrobenzene on fluorescence response of the sensor can be as low as $470.00 \mathrm{M}-1,359.94 \mathrm{M}-1,3.62^{*} 103 \mathrm{~mL}-1,2.10^{*} 10-5 \mathrm{M}, 5.73^{*} 10-5 \mathrm{M}, 1.24^{*} 10-5 \mathrm{~mL}$, respectively. On the contrary, It is applied to detected for toluene and xylene as a turn-on chemosensor in DMF. The quenching constant and detection of limit for toluene and xylene on fluorescence response of the sensor can be as low as $-11.05 \mathrm{~mL}-1,-6.23 \mathrm{~mL}-1$, $9.30 * 10-4 \mathrm{~mL}, 7.35 * 10-3 \mathrm{~mL}$, respectively. The application of water sample and vegetables showed that the $\mathrm{L}$ had high sensitive detection for $\mathrm{Fe} 3+$ ions. Meanwhile the application of gasoline, diesel and engine oil showed that the L had high sensitive detection for toluene and xylene.
\end{abstract}

\section{Hosted file}

Manuscript.pdf available at https://authorea.com/users/368602/articles/487916-designsynthesis-of-nitrogen-rich-triazine-derivatives-and-its-application-in-water-samplevegetables-and-oil-product

\section{Hosted file}

coverletter.pdf available at https://authorea.com/users/368602/articles/487916-designsynthesis-of-nitrogen-rich-triazine-derivatives-and-its-application-in-water-samplevegetables-and-oil-product 